\title{
ProteÇÃo dA VitalidAdE dENTINO-PULPAR EM OdONTOPEDIATRIA: UMA REVISÃO DE LITERATURA
}

\author{
Dentin-pulp protection in pediatric dentistry: a review
}

\author{
Ana Gabriela Bausenª (Deovana Lougon Moulin ${ }^{a}$ \\ Karen Cassano ${ }^{a}$, (D) Ana Luiza Peres Baldiottib (D) Angela Scarparoc
}

\section{RESUMO}

A dentina e a polpa são consideradas substratos interdependentes, conhecido como complexo dentino-pulpar. Frente a injúrias como cárie e traumatismo, deve-se realizar a proteção desse complexo, baseando-se na inserção de materiais restauradores considerados agentes protetores. Os materiais considerados ideais devem apresentar propriedades como: biocompatibilidade, ser antimicrobiano, ser insolúvel ao meio bucal, ser isolante térmico e elétrico, ter potencial terapêutico e propriedades mecânicas adequadas. Como essas características não são encontradas em todos os materiais, é importante que o cirurgião-dentista conheça as vantagens e as desvantagens daqueles que estão disponíveis comercialmente. O objetivo deste trabalho foi realizar uma revisão crítica da literatura sobre os materiais indicados para proteção indireta da vitalidade dentino-pulpar (PVDP), em dentes decíduos. Para isso, foram pesquisados livros, teses, dissertações, monografias, artigos impressos e das bases de dados, PubMed, SciELO e MEDLINE. De acordo com a literatura, observou-se que a garantia de êxito na proteção da vitalidade dentino-pulpar é alcançada por meio de um ótimo selamento marginal, impedindo a infiltração bacteriana na dentina e controlando a progressão da cárie. São necessários mais estudos clínicos que avaliem outros desfechos após o tratamento indireto da polpa. Não existe um material que possua todas as características desejadas para a PVDP, e estudos recentes demostram que a chave não se encontra no material protetor, mas sim na vedação marginal das restaurações, propiciando a inativação da progressão da cárie dentária.

Palavras-chave: Hidróxido de cálcio. Polpa dentária. Dentina. Dente decíduo. Materiais dentários.

\begin{abstract}
Dentin and pulp are considered interdependent substrates, known as the dentin-pulp complex. In front of injuries such as caries and trauma, this complex should be protected with restorative materials considered to be protective agents. An ideal material should have properties such as biocompatibility, be antimicrobial, be insoluble in the oral environment, be thermal and electrically insulating, have therapeutic potential, and adequate mechanical properties. As these characteristics are not found in all materials, the dentist must know the advantages and disadvantages of those that are available. This study aimed to perform a critical review of the indirect materials indicated for the protection of dentin-pulp vitality (PDPV) to ensure the success of indirect pulp treatment in primary teeth. A search was carried out in books, theses, dissertations, monographs, printed articles and databases, PubMed, SciELO, and MEDLINE. According to the literature, the success in protecting the dentin-pulp vitality is achieved through an excellent marginal seal, preventing bacterial infiltration in the dentin and controlling the progression of caries. Further clinical studies are needed to evaluate other outcomes after indirect pulp treatment. There isn't a material that has all the desired characteristics for PDPV, and recent studies show that the key to PDPV isn't found in the protective material, but in the restorations marginal sealing, enabling the inactivation of the progression of dental caries.
\end{abstract}

Keywords: Calcium hydroxide. Dental pulp. Dentin. Tooth, deciduous. Dental materials.

\footnotetext{
a Bolsista PET Odontologia ISNF/UFF; Graduada em Odontologia, Instituto de Saúde de Nova Friburgo (ISNF); Universidade Federal Fluminense (UFF), Nova Friburgo, RJ, Brasil.

${ }^{\mathrm{b}}$ Mestranda no Departamento de Saúde Bucal da Criança e do Adolescente, Universidade Federal de Minas Gerais (UFMG), Belo Horizonte, MG, Brasil. ${ }^{c}$ Professora do curso de Odontologia do Instituto de Saúde de Nova Friburgo (ISNF), Universidade Federal Fluminense (UFF), Nova Friburgo, RJ, Brasil.
}

Autor de correspondência: Angela Scarparo - E-mail: angelascarparo@id.uff.br

Data de envio: 02/06/2020 | Data de aceite: 08/07/2020 


\section{INTRODUÇÃO}

A cárie dentária ainda atinge cerca de 600 milhões de crianças em todo o mundo ${ }^{1}$, e com a ocorrência de traumatismos dentários na infância ${ }^{2,3}$, há frequentemente a necessidade de realizar a proteção pulpar a fim de conservar o dente decíduo com vitalidade até à sua exfoliação fisiológica ${ }^{4}$.

A dentina e o tecido pulpar são estruturas co-dependentes, e formam juntas o complexo dentino-pulpar. Há longos anos, é reforçado que, frente a agressões, como lesões de cárie profundas e traumatismos, é necessária a proteção destes tecidos ${ }^{5-9}$.

A proteção da vitalidade dentino-pulpar (PVDP) baseia-se na capacidade de redução do número de bactérias viáveis remanescentes, remineralização de tecidos duros desmineralizados, indução da dentina reacionária e proteção da integridade da polpa. A PVDP pode ser alcançada de várias maneiras, dependendo das necessidades individuais do caso, do material e da técnica empregada ${ }^{8}$. A PVDP é baseada na aplicação de agentes protetores ${ }^{10}$, sendo que diversos materiais podem ser utilizados para o tratamento indireto da polpa, como: hidróxido de cálcio; agregado trióxido mineral; cimento de ionômero de vidro convencional ou modificado por resina; cimento de óxido de zinco e eugenol; condicionamento ácido e sistema adesivo?.

Os agentes protetores deveriam ser biocompatíveis, antimicrobianos, insolúveis ao meio bucal, apresentar potencial terapêutico e adequadas propriedades mecânicas, capacidade de isolamento térmico e elétrico. Além de não interferir nas propriedades do material restaurador e possuir adesividade às estruturas dentárias, com um perfeito selamento da dentina ${ }^{11}$.

Porém, não existe um material ideal, sendo que cada um apresenta suas propriedades, tornando-se ímpar o cirurgião-dentista conhecer as vantagens, desvantagens, e o que os estudos mais recentes mostram sobre a PVDP. Diante da variedade de materiais a serem empregados e a necessidade de manter o dente decíduo com vitalidade até à sua exfoliação fisiológica, o objetivo deste trabalho foi realizar uma revisão crítica da literatura sobre os materiais indiretos utilizados para a realização da PVDP.

\section{REVISÃO DA LITERATURA}

\section{O complexo dentino-pulpar}

O grande desafio de obter estabilidade das restaurações à longo prazo, encontra-se na sensibilidade do tecido dentinário. A dentina, tecido composto majoritariamente por matéria orgânica, possui estrutura complexa formada, principalmente, por túbulos dentinários, prolongamentos odontoblásticos, fluido e dentina peritubular ${ }^{8}$. Os prolongamentos odontoblásticos, localizados no interior dos túbulos dentinários, estão diretamente relacionados com os mecanismos fisiológicos de defesa do complexo dentino-pulpar ${ }^{12,13}$.

A dentina e o tecido pulpar são originados da mesma estrutura embriológica e continuam unidos durante toda vida funcional do dente ${ }^{14}$. Por isso, estes tecidos são abordados como uma estrutura única, sendo que as injúrias na dentina alcançam o tecido pulpar ${ }^{15}$. Portanto, a importância da escolha do material protetor, que deve além de auxiliar, não atrapalhar o próprio potencial reparador dos tecidos. 


\section{Proteção direta X Proteção indireta}

A proteção pulpar direta, também denominado capeamento pulpar direto, caracteriza-se pela inserção de material restaurador sobre a polpa acidentalmente exposta durante trauma ou remoção do tecido cariado. Esta manobra tem por objetivo estimular a formação de dentina reacional, e com isso manter a vitalidade pulpar. Desta forma, estão indicados apenas em casos de dentes assintomáticos, em que o campo operatório esteja livre de umidade (isolamento absoluto da umidade), e a hemostasia seja observada após limpeza da cavidade confirme preconizado pela técnica ${ }^{16}$.

Já a proteção pulpar indireta ou capeamento pulpar indireto, é caracterizado por ser um tratamento conservador, visto que preconiza a remoção parcial da dentina cariada, com o intuito de preservar estrutura dentária, e assim evitar a exposição pulpar. Estão indicados dentes com lesões cariosas profundas, sem sintomatologia dolorosa e sem sinais de alteração pulpar irreversível ${ }^{17}$.

\section{Materiais protetores do complexo dentino-pulpar}

A profundidade da cavidade e a espessura de dentina remanescente foram tidos como parâmetros para a escolha do material protetor por longos anos ${ }^{18}$. No entanto, não existe unanimidade na literatura sobre a profundidade da cavidade em função de valores quantitativos ${ }^{11}$.

Estudos recentes demonstram que os materiais empregados na PVDP não têm apresentado diferenças estatisticamente e/ou clinicamente significativas, pois o selamento da cavidade é o que determina o sucesso ${ }^{19}$. Portanto, o material de escolha seria o mais resistente, que apresente menor chance de insucesso ao selamento ${ }^{10}$ e que não interfira na própria capacidade do complexo dentino-pulpar de se regenerar.

\section{Verniz cavitário}

O verniz cavitário foi muito usado com o objetivo de selar o espaço entre as restaurações em amálgama e a estrutura dentária remanescente. Era esperado que este material impedisse a penetração de substâncias corantes e produtos irritantes, oriundos de materiais restaurados ${ }^{16}$. Entretanto, por ser muito solúvel, não era eficiente em dentina, além de ser um fraco isolante térmico, tornando ultrapassado seu uso como PVDP ${ }^{6,20}$.

Estudos demonstraram que este material não é um adequado protetor do complexo dentino-pulpar, principalmente quando se utiliza ligas com baixo teor de produtos de corrosão. Ainda, estudos relataram que a utilização do verniz cavitário favoreceu a microinfiltração marginal ${ }^{8}$.

Devido a estas características indesejáveis, e à era da odontologia adesiva que levou a infrequente utilização do amálgama, este material caiu em desuso.

\section{Selantes}

Os selantes possuem um elevado escoamento, sendo um bom material de substituição dos vernizes cavitários em relação a prevenção de microinfiltração marginal ${ }^{6}$. No entanto, não há informações suficientes na literatura quanto ao seu uso com objetivo de PVDP $^{8}$, sendo que nos trabalhos existentes, não há indicação do mesmo para esse fim ${ }^{21}$.

Atualmente, estes materiais são amplamente empregados no selamento de margens, sulcos, fendas e pequenas fraturas, e também no condicionamento de restaurações diretas ou indiretas ${ }^{18}$. 


\section{Cimento de ionômero de vidro}

O cimento de ionômero de vidro (CIV) possui propriedades como: a liberação de flúor, biocompatibilidade, ação antimicrobiana, adesividade com os tecidos, e coeficiente de expansão térmica e módulo de elasticidade semelhantes ao da dentina ${ }^{8,22}$, o que possibilita um adequado selamento marginal da restauração, a médio e longo prazo ${ }^{23}$. Tais propriedades os tornam excelentes materiais para proteção pulpar indireta ${ }^{20}$.

Existem diversos tipos e marcas de CIVs no mercado, com diferentes indicações, composições e viscosidades, que devem ser selecionadas de acordo com sua indicação clínica $^{20}$. Contudo, a literatura mostra que os CIVs convencionais apresentam longo tempo de geleificação (presa), alto grau de solubilidade e degradação (quando expostos ao meio bucal), propriedades mecânicas insatisfatórias (em áreas de esforços mastigatórios), além de serem susceptíveis à desidratação e provocarem alteração na coloração dos compósitos odontológicos ${ }^{24,25}$.

O cimento de ionômero de vidro modificado por resina foi criado para que essas limitações fossem supridas. Ao incorporar monômeros resinosos, houve um favorecimento nas propriedades mecânicas do material ${ }^{26}$. Porém, assim como ocorre na hibridização, essa incorporação de monômeros fez com que houvesse um aumento do efeito citotóxico, se comparado com o CIV convencional ${ }^{13,22,25}$.

Os CIVs apresentam-se como adequados materiais para PVDP, pois possuem bom custo-efetividade ${ }^{27}$, fácil aplicação, e dependendo do ciclo biológico do dente decíduo, é um material definitivo e eficaz. Os CIVs, convencional e modificado por resina, são bons materiais e amplamente utilizados em Odontopediatria, tanto como material provisório, base, ou definitivo ${ }^{8}$.

\section{Cimento de óxido de zinco e eugenol}

O cimento de óxido de zinco e eugenol (OZE) apresenta um isolamento térmico satisfatório, estimula a formação de dentina reparadora, possui alta solubilidade, baixa estabilidade e baixas propriedades mecânicas. Dessa forma, pode ser utilizado apenas para selamento provisório de cavidades, como para base de restaurações ${ }^{20,28}$.

Entretanto, antes de formar a dentina reparadora, este material pode acarretar em uma reação inflamatória crônica na polpa ${ }^{19}$. E ainda, em virtude da presença do eugenol, pode ocorrer falhas na ação dos sistemas adesivos. Diante disso, a indicação do cimento de óxido de zinco e eugenol para proteção do complexo dentino pulpar é rara ${ }^{8}$.

\section{Agregado trióxido mineral}

O agregado trióxido mineral (MTA), apresenta ótimas propriedades físicas e químicas, sendo considerado um excelente material para tratamentos pulpares. Este material é bastante indicado em dentes permanentes, e apesar de não haver ainda muitos estudos em dentes decíduos, as investigações existentes possuem resultados satisfatórios e apoiam sua utilização na odontopediatria ${ }^{9}$.

O MTA é um material biocompatível, com adequado selamento marginal, efeito antibacteriano, não é tóxico, estimula a formação de tecido mineralizado e a regeneração tecidual do periodonto ${ }^{25}$. Estudos já demonstram que frente ao capeamento pulpar direto, o uso de MTA foi tão eficaz quanto ao do hidróxido de cálcio, sendo um material adequado para PVDP ${ }^{29}$.

Somado a isso, os tratamentos com MTA apresentaram menos inflamação, hiperemia e necrose. Contudo, uma desvantagem deste material é o longo tempo de presa e seu elevado custo, que o torna inviável em termos de políticas públicas. 


\section{Hidróxido de cálcio}

O cimento de hidróxido de cálcio apresenta ótima compatibilidade biológica e ação antibacteriana. Contudo, alguns estudos relatam que os cimentos de hidróxido de cálcio se dissolvem em contato com os materiais restauradores, resultando em infiltração marginal23.

Além de ser um material de baixo custo, o hidróxido de cálcio estimula à formação de uma barreira composta por minerais ${ }^{8}$. Este material é comercialmente disponibilizado em duas apresentações: pó e pasta, sendo que para a proteção indireta do tecido pulpar, é recomendada a pasta.

O cimento de hidróxido de cálcio é amplamente utilizado, sendo a principal escolha pelos clínicos para PVDP. Este material já foi extensivamente estudado, e é frequentemente utilizado como principal opção em experimentos de biocompatibilidade, graças a seu efeito no reparo da polpa ${ }^{25}$.

Porém estudos mais recentes tem demostrado grande falha por parte deste material, tornando questionável até que ponto seu amplo uso tem sido a melhor escolha?.

\section{Sistemas adesivos}

Com a revolução da odontologia adesiva nas últimas duas décadas, e com a era da odontologia minimamente invasiva, a utilização dos procedimentos restauradores adesivos cresceram em larga escala. Os materiais disponíveis no mercado são cada vez de mais simples aplicação e excelência na adesão, o que permite menor tempo clínico, que é um facilitador na Odontopediatria.

Graças às propriedades adesivas de melhor adaptação nas paredes da cavidade, isolamento térmico e eletrolítico e selamento dos túbulos dentinários, estudos recentes demostram que mesmo em cavidades profundas, a aplicação do sistema adesivo de forma correta é capaz de promover adequada PVDP ${ }^{7,30,31}$.

As técnicas adesivas auxiliam na proteção e consequente regeneração pulpar, uma vez que mantêm a interface entre dente e resta]uração livre de microrganismos, tem papel fundamental na retenção da restauração, selamento dos túbulos dentinários, prevenção de microinfiltração e ainda isolamento térmico, químico e mecânico ${ }^{6}$.

Nos casos de cavidades médias ou rasas, essa técnica é utilizada há longos anos, porém, em cavidades profundas essa técnica não era considerada ideal devido a um possível potencial citotóxico para polpa ${ }^{15,25}$, entretanto, estudos atuais descreem dessa possibilidade, sendo a técnica menos invasiva e mais atual ${ }^{13,32}$. Contudo, mais estudos são necessários para executarmos esse procedimento com forte evidência científica.

\section{Técnica operatória - Remoção seletiva de cárie}

Com o intuito de minimizar o risco de exposição pulpar e preservar o máximo de estrutura dentinária, ao longo da última década vários estudos tem demonstrado o sucesso da remoção seletiva de cárie ${ }^{19,33,34}$. A técnica consiste na remoção total da dentina cariada das paredes circundantes e na remoção seletiva da parede pulpar, removendo assim, apenas o tecido necrótico e amolecido. O sucesso é baseado na remoção de todo tecido cariado das paredes circundantes, permitindo um adequado vedamento e consequente ausência de substrato, o que inativa a lesão, propiciando a recuperação da dentina remanescente $e^{7,30,35}$.

Inicialmente a técnica era realizada em duas sessões e com a utilização de um material protetor, geralmente o cimento de ionômero de vidro convencional ou cimento de hidróxido de cálcio ${ }^{36}$. Entretanto, a necessidade da reabertura da cavidade demonstrou-se desnecessária e uma revisão sistemática recente demonstrou a capacidade de recuperação da lesão sem 
um material forrador, podendo ser utilizado apenas o sistema adesivo, evidenciando que a própria dentina é o melhor material protetor ${ }^{37}$.

Essa técnica permite os melhores resultados em termos de progressão da lesão de cárie e longevidade das restaurações, assim como a preservação do tecido pulpar, uma vez que fundamenta-se na capacidade defensiva e reparativa do complexo dentino-pulpar ${ }^{33}$.

\section{DISCUSSÃo}

A cárie dentária continua sendo um problema de saúde pública, afetando milhões de crianças em todo mundo, e os traumatismos dentários são comuns de ocorrer na infância. Diante disso, há frequentemente a necessidade PVDP, afim da manutenção dos dentes decíduos até seu período de exfoliação.

O cimento de hidóxido de cálcio, ainda é o material mais utilizado para este fim ${ }^{23}$, porém, estudos recentes questionam e comparam a utilização do mesmo ${ }^{9,31}$. Alguns estudos já relataram que o uso do cimento de hidróxido de cálcio seria dispensável, não sendo essencial para forramento ${ }^{38,39}$.

Há um consenso de que o principal objetivo do hidróxido de cálcio é provocar a remineralização e, consequentemente, proteção da polpa ${ }^{33,37,39}$. Contudo, dentes tratados com cimento de ionômero de vidro modificado por resina (CIV-MR) ou com hidróxido de cálcio resultaram em uma espessura de dentina reparativa similar ${ }^{9,40}$.

Uma revisão sistemática analisou a influência do CIV-MR, hidróxido de cálcio e MTA, no sucesso clínico de tratamento pulpar indireto em dentes decíduos, e relataram que o tipo de material não teve grande interferência no risco de falha do tratamento. Porém, o hidróxido de cálcio apresentou maior chance de falhas quando comparado ao CIV-MR, guta-percha e sistema adesivo ${ }^{9}$.

Rosa et al. ${ }^{37}$ constataram que existem poucos indícios para apoiar o uso de hidróxido de cálcio como agente forrador. Na dentição decídua, o nível de indicação foi equilibrado ao ser comparado com o CIV-MR, e baixo quando comparado com materiais inertes ou sistemas adesivos. O que vai de acordo com o estudo de Santos et al. ${ }^{9}$, que demonstraram que o CIV-MR apresentou menor chance de incidir em risco pulpar.

Levando em consideração os benefícios, como liberação de flúor, baixa sensibilidade pós-operatória e menor chance de falha do operador, os cimentos de ionômero de vidro são considerados uma opção para o tratamento pulpar indireto em dentes decíduos. E por apresentar ótimas propriedades biológicas, físicas e mecânicas, tem demonstrado ser uma opção satisfatória na eleição do material, quando comparado ao hidróxido de cálcio.

Como foi descrito por Peliz et al. ${ }^{14}$, em 2005, a técnica de hibridização levou a uma diminuição da microinfiltração marginal, quando comparado a materiais como cimento de ionômero de vidro e hidróxido de cálcio. Há autores que concordam que os sistemas adesivos produzem resultados similares com os do hidróxido de cálcio ${ }^{31,41}$. Büyükgüral e Cehreli ${ }^{42}$ registraram que tanto o sistema adesivo autocondicionante, quanto o convencional não apresentaram insucesso clínico ou radiográfico sem o uso do cimento de hidróxido de cálcio como forrador em um período de 24 meses.

Em estudos que avaliaram a condição pulpar de dentes com lesões profundas de cárie, radiograficamente e clinicamente, levando em consideração cor, consistência, avaliações histológicas e microbiológicas e microdureza, comprovaram que após utilizarem hidróxido de cálcio, cimento de ionômero de vidro ou adesivo autocondicionante, ocorreu a formação de dentina terciária, independente do agente utilizado ${ }^{33,43,44}$. Porém, devemos levar em 
consideração que a resina composta e cimento de ionômero de vidro cumprem as funções protetoras e restauradoras concomitantemente ${ }^{19}$.

É indicado usar sobre a dentina desmineralizada remanescente um material que seja biologicamente compatível, e estudos demonstram que a inativação da lesão de cárie pode ser alcançada ainda que seja utilizado materiais inertes como a guta-percha e até mesmo cera. Isso ressalta que a dentina cariada pode ficar confinada se as margens da restauração estiverem vedadas . Com a utilização destes materiais alcançamos uma taxa de sucesso semelhante ao uso de cimento de hidróxido de cálcio ${ }^{30}$. Os estudos que compararam o sucesso destes materiais relatam que em ambos os grupos, a contaminação diminuiu com o tempo $0^{9,32,33,37,45}$.

Não existe um material ideal que apresente todas as características desejadas, e mais ensaios clínicos randomizados controlados são necessários para podermos escolher com segurança o melhor agente protetor. Na hora da escolha deste agente, o profissional deve levar em consideração as evidências científicas, a técnica que será empregada ${ }^{8}$ e é importante o entendimento de que o complexo dentino-pulpar é um sistema rico, e com grande capacidade reparadora. O material protetor não deve influenciar negativamente os tecidos de desempenharem suas funções e se possível, devem auxiliar no reparo/proteção.

Apesar do uso do cimento de hidróxido de cálcio ser benéfico para o complexo dentino-pulpar devido as suas características biocompatíveis, a sua utilização pode ser dispensável, uma vez que a taxa de sucesso do tratamento pulpar indireto em dentes decíduos, quando comparado a outros materiais, é similar. Em geral, verificou-se que há poucas evidências clínicas que sustentem o uso do cimento de hidróxido de cálcio, mesmo que ainda seja usado por muitos clínicos em tratamentos de lesões profundas de cárie.

Acredita-se que o êxito do tratamento pulpar indireto é alcançado quando se realiza um adequado selamento marginal, o que impedirá a infiltração bacteriana e a progressão da cárie. Deste modo, os materiais para PVDP não apresentam diferenças significativas para o sucesso do tratamento. Dessa forma, a melhor opção é lançar mão de materiais que apresentam adequada resistência mecânica e pequena chance de insucesso ao vedamento marginal.

Dado o exposto, mais estudos com maior tempo de acompanhamento acerca deste tema devem ser produzidos para comprovar os desfechos dos materiais de PVDP em dentes decíduos.

\section{Conclusão}

Não existe um material que possua todas as características desejadas para a PVDP. Além disso, estudos recentes tem demostrado que a chave para a PVDP não se encontra no material protetor, e sim na vedação marginal das restaurações, propiciando a inativação da progressão da cárie dentária.

\section{REFERÊNCIAS}

1. Tinanoff N, Baez R], Diaz Guillory C, Donly K], Feldens CA, McGrath C, et al. Early childhood caries epidemiology, aetiology, risk assessment, societal burden, management, education, and policy: Clobal perspective. Int] Paed Dent. 2019 May;29(3):238-48

2. Dharmani CK, Pathak A, Sidhu HS. prevalence of traumatic dental injuries to anterior teeth in 8-12-year-old schoolchildren of Patiala City, Punjab, India: An Epidemiological study. Int] Clin Pediatr Dent. 2019 Jan-Feb;12(1):25-9.

3. Zaleckiene V, Peciuliene V, Aleksejüniené ], Drukteinis S, Zaleckas L, Brukiene V. Dental trauma experience, attitudes and trauma prevention in 11-to 13-year-old Lithuanian schoolchildren. Oral Health Prev Dent Oral Health Prev Dent. 2020;18(2):373-8. 
4. Silva CC, Andrade DC, Edo MM, Leache EB. Agregado de trióxido mineral (MTA) Aplicações em odontopediatria. Revista da Ordem dos Médicos Dentistas. 2010 Ago;7:14-22.

5. Leinfelder KF. Changing restorative traditions: the use of bases and liners. ] Am Dent Assoc. 1994 Jan;125(1):65-7.

6. Ritter AV, Swift Jr E]. Current restorative concepts of pulp protection. Endod Topics. 2003 Feb;5(1):41-8.

7. Marchi J], Araújo FB, Fröner AM, Straffon LH, Nör JE. Indirect pulp capping in the primary dentition: a 4 year follow-up study. J Clin Pediatr Dent. 2006 Jan;31(2):68-71.

8. Freires IA, Cavalcanti YW. Proteção do complexo dentino-pulpar: indicações, técnicas e materiais para uma boa prática clínica. RBPS Braz] Health Res. 2011;13(4):69-80.

9. Santos PS, Pedrotti D, Braga MM, Rocha RO, Lenzi TL. Materials used for indirect pulp treatment in primary teeth: a mixed treatment comparisons meta-analysis. Braz Oral Res. 2017 Dec;31:e101.

10. Garcia FM, Braga MM, Mendes FM, Novaes TF, Matos R, Imparato JCP. Capeamento pulpar indireto com sistema adesivo e resina composta 42 meses de acompanhamento. J Health Sci Inst. 2009;27(4):417-21.

11. Hebling ], Ribeiro APD, Costa CAS. Relação entre materiais dentários e o complexo dentino-pulpar. Rev Odontol Bras Central. 2010;48(18):1-9.

12. Pashley DH, Carvalho RM. Dentine permeability and dentine adhesion. J Dent. 1997 Sep;25(5):355-72

13. Ribeiro APD, Sacono NT, Soares DG, Bordini EAF, Costa CAS, Hebling J. Human pulp response to conventional and resin-modified glass ionomer cements applied in very deep cavities Clin Oral Investig. 2020 May;24(5):1739-48.

14. Peliz MIL, Duarte Jr S, Dinelli W. Scanning eléctron microscope analysis of internal adaptation of materials used for pulp protection under composite resin restorations. ] Esthet Restor Dent. 2005;17(2):118-28.

15. Huang FM, Li YC, Lee SS, Chang YC. Cytotoxicity of dentine bonding agents on human pulp cells is related to intracellular glutathione levels.] Int Endod. 2010 Dec;43(12):1091-7.

16. Fuks AB. Vital pulp therapy with new materials for primary teeth: new directions and treatment perspectives. Pediatr Dent. 2008 May-Jun;30(3):211-9.

17. AAPD. American Academy on Pediatric Dentistry Clinical Affairs Committee-Pulp Therapy Subcommittee. Cuideline on pulp therapy for primary and young permanent teeth. Pediatr Dent. 2008-2009;30(7 Sup-pl):170-4.

18. Silva AF, Piva E, Demarco FF, Correr L, Osinga PW. Microleakage in conventional and bonded amalgam restorations: influence of cavity volume. Oper Dent. 2006;31(3):377-83.

19. Casagrande L, Falster CA, Di Hipolito V, De Goés MF, Straffon LH, Nör JE, et al. Effect of adhesive restorations over incomplete dentin caries removal: 5-year follow-up study in primary teeth. J Dent Child. 2009 May-Aug;76(2):117-22.

20. Loguercio AD, Reis A, Minto AMP, Mandarino F. Agentes para proteção do complexo dentinopulpar: cimentos odontológicos. In: Reis A, Loguercio AD. Materiais dentários diretos: dos fundamentos à aplicação clínica, Ed. Santos: São Paulo; 2007. p.55-90.

21. Takanashi PT, Silva LMP, Komori PCP, Rode SM. Avaliação da indicação de materiais para proteção do complexo dentino-pulpar. Ciênc Odontol Bras. 2010;13(4):22-8.

22. Duque C, Hebling ], Smith A], Giro EM, Oliveira MF, de Souza Costa CA. Reactionary dentinogenesis after applying restorative materials and bioactive dentin matrix molecules as liners in deep cavities prepared in nonhuman primate teeth. J Oral Rehabil. 2006 Jun;33(6):452-61.

23. Filther AZ, Schrederhof VCV, Silva MAR, Piemonte MR, Lima CP, Kirchhoff AL, et al. A importância do complexo dentino pulpar no restabelecimento dentinário. Rev Gest Saúde. 2016;14(2):13-9.

24. Cruvinel DR, Garcia LFR, Consani S, Pires-de-Souza FCP. Composites associated with pulp-protection material: color-stability analysis after accelerated artificial aging. Eur ] Dent. 2010 ]an;4(1):6-11.

25. Modena KCS, Casas-Apayco LC, Atta MT, Costa CAS, Hebling ], Sipert CR, et al. Cytotoxicity and biocompatibility of direct and indirect pulp capping materials. J Appl Oral Sci. 2009 Nov-Dec;17(6):544-54

26. Tedesco TK, Calvo AF, Yoshioka L, Fukushima KA, Cesar PF, Raggio, DP. Does acid challenge affect the properties and bond stability of restorative materials on primary teeth?] Adhes Dent. 2018 May;20(3):223-31.

27. Goldman AS, Chen X, Fan M, Frencken JE. Cost effectiveness, in a randomized trial, of glass ionomer based and resin sealant materials after 4 yr. Eur ] Oral Sci. 2016 Oct;124(5):472-9.

28. Pires-de-Sousa FCP, Contente MMMG, Casemiro LA. Cianoacrilato como protetor superficial de restaurações de cimento de óxido de zinco e eugenol e de cimento de ionômero de vidro: avaliação da infiltração marginal. Ciênc Odontol Bras. 2006;9(1):47-53.

29. Queiroz AM, Assed S, Leonardo MR, Nelson-Filho MR, Nelson-Filho P, Silva LAB. MTA and calcium hydroxide for pulp capping. J Appl Oral Sci. 2005 Apr-Jun;13(2):126-30

30. Maltz M, Oliveira EF, Fontanella V, Bianchi R. A clinical microbiologic and radiographic study of deep carious lesions after incomplete caries removal. Quintessence Int. 2002 Feb;33(2):151-9.

31. Cut C, Zhou XN, Chen WM. Self-etching adhesives: possible new pulp capping agentes to vital pulp therapy. Front Med. 2011 Mar;5(1):77-9. 
32. Silva GSQ, Raggio DP, Machado GFR, Mello-Moura ACV, Gimenez T, Floriano I, et al. Impact of different restorative treatments for deep caries lesion in primary teeth (CEPECO 1)-study protocol for a noninferiority randomized clinical trial. BMC Oral Health. 2019;19(1):6.

33. Franzon R, Casagrande L, Pinto AS, García-Codoy F, Maltz M, Araújo FB. Clinical and radiographic evaluation of indirect pulp treatment in primary molars: 36 months follow-up. Am ] Dent. 2007 Jun;20(3):189-92.

34. Bjorndal L, Simon S, Tomson PL, Duncan HF. Management of deep caries and the exposed pulp. Int Endo ]. 2019;52(7):949-73.

35. Schwendicke F, Frencken]E, Bjorndal L, Maltz M, Manton D], Ricketts D, et al. Managing carious lesions: consensus recommendations on carious tissue removal. Adv Dent Res. 2016 May;28(2):58-67.

36. Ricketts D. Management of the deep carious lesion and the vital pulp dentine complex. British Dent ]. 2001 Dec;191(11):606-10.

37. da Rosa WLO, Lima VP, Moraes RR, Piva E, da Silva AF. Is a calcium hydroxide liner necessary in the treatment of deep caries lesions? - A systematic review and meta-analysis. Int Endod J. 2018 May;52(5):588-603.

38. Coll JA, Seale NS, Vargas K, Marghalani AA, AI Shamli S, Graham L. Primary tooth vital pulp therapy: a systematic review and meta-analysis. Pediatr Dent. 2017 Feb;39(1):16-27.

39. Schwendicke F, Gostemeyer G, Gludd C. Cavity lining after excavating caries lesions: meta-analysis and trial sequential analysis of randomized clinical trials. J Dent. 2015 Nov;43(11):1291-7.

40. Mathur V, Dhillon ], Logani A, Kalra G. Evaluation of indirect pulp capping using three different materials: a randomized control trial using cone-beam computed tomography. Indian ] Dent Res. 2016 Nov-Dec;27(6):623-9.

41. Olmez A, Oztas N, Basak F, Sabuncuoglu B. A histopathologic study of direct pulp-capping with adhesive resins. Oral Surg Oral Med Oral Pathol Oral Radiol Endod. 1998 Jul;86(1):98-103.

42. Büyükgüral B, Cehreli ZC. Effect of different adhesive protocols vs calcium hydroxide on primary tooth pulp with different remaining dentin thicknesses:24-month results. Clin Oral Investig. 2008 Mar;12(1):91-6.

43. Marchi J], Froner AM, Alves HLR, Bergman CP, Araújo FB. Analysis of primary tooth dentin after indirect pulp capping. J Dent Child. 2008 Sep-Dec;75(3):295-300

44. Dalpian DM, Casagrande L, Franzon R, Dutra GMC, Araújo FB. Dentin microhardness of primary teeth undergoing partial carious removal. J Clin Ped Dent. 2012 Summer;36(4):363-7.

45. Pinto AS, Araújo FB, Franzon R, Figueiredo MC, Henz S, Garcia-Godoy F. Clinical and microbiological effect os calcium hydroxide protection in indirect pulp capping in primary teeth. ] Dent. 2006 Dec;19(6):382-6. 